\title{
A Look Back in Time: Sir Robert Jones, 'Father of Modern Orthopaedics'
}

\author{
WYW Tham, MBBS, SMC Sng, MS Orth, YM Lum, MS Orth, YH Chee, FRCSEd (Edin) \\ Division of Musculoskeletal Trauma Surgery University Orthopaedics, Hand \& Reconstructive Microsurgery \\ Cluster, National University Hospital, Singapore
}

\begin{abstract}
This paper describes the life of Sir Robert Jones, from his humble beginnings as an apprentice of Thomas Smith, to his many contributions to the orthopaedic specialty. Robert Jones' passion and interest in the subject led to its advancement from a specialty that dealt mainly with crippling diseases in children, to that of treating and rehabilitating disabled adults. He revolutionized the practice by integrating the use of plain radiography, and by developing many new surgical and procedural techniques. He largely improved the specialty by publishing many textbooks and papers, and trained many orthopaedic surgeons from within England and internationally. The purpose of this paper seeks to provide a platform for readers to learn about the man behind the Jones fracture and bandage. It will help readers understand how one man's passion for orthopaedics helped transform it into a specialty in its own rights.
\end{abstract}

Key Words:

Robert Jones, Orthopaedics, Establishing the specialty

\section{INTRODUCTION}

Robert Jones was born on 28 June 1857, in Rhyle, Wales. Through his interest and work in the field, Robert Jones helped establish orthopaedics as a surgical specialty. His practice had wide influence on orthopaedics both nationally and internationally, especially in America. Robert Jones also made discoveries and developed many surgical techniques in the field of orthopaedics, many which are named after him. He was conferred the rank of Major General during the First World War, and knighted. He received recognition and degrees from institutes in Europe and North America, to name a few of his achievements. Robert Jones also had a passion for public health, dedicating time to the study and education on prevention and cure of children with deformities and adults with disabilities. He worked on removing the stigma society had on cripples, helping them reintegrate back into society. Robert Jones' work had strong influence on the practice of orthopaedics in his life time, and even many years after his death. Robert Jones developed orthopaedics into a specialty.

\section{Early Life and Work}

Robert Jones was born on 28 June 1857 in Rhyl, North Wales, and was brought up in London. He studied in a private school, Sydenham College, in London before moving to live with his uncle, Hugh Owen Thomas, in Liverpool at the age of 16 . He worked for his uncle, learning about fracture care and the manufacture of braces and studied in the Liverpool School of Medicine from 1873 to 1878 . In 1881 , Robert Jones was appointed as an assistant surgeon in Liverpool Stanley Hospital and was subsequently elevated to the position of surgeon in 1886. He obtained the FRCS (Fellowship of the Royal College of Surgeons) Edinburgh. In 1889 and in the same year, he was appointed as the honorary surgeon and Dean of the Clinical School of the Royal Southern Hospital ${ }^{2,4}$.

\section{Manchester Ship Canal}

Robert Jones was appointed the Surgeon-Superintendent for the construction of the Manchester Ship Canal, which commenced in 1887. To ensure efficiency, Robert Jones divided the canal into three sections, each having its own hospital and external medical staff, all of which he personally designed and staffed.

Robert Jones' work here provided him with invaluable experience, especially in emergency surgical work. In addition, the experience he gained in organization and in dealing with men would prove invaluable during his service in the First World War ${ }^{2}$.

\section{Establishing the Specialty}

On 3rd November 1894, a group of surgeons led by Robert Jones and Alfred Tubby convened at the Holborn Restaurant in London and formed the British Orthopaedic Society. There were thirty-one members. Unfortunately, the society ceased to function after four years, mainly due to most members being general surgeons and being not fully 
committed to orthopaedic practice ${ }^{5}$. Nevertheless, Robert Jones was committed to improving orthopaedic care and fostering the specialization of orthopaedics.

He was largely unhappy with the lack of importance placed on orthopaedics, and often criticized the way fractures were being treated in what he termed "big teaching hospitals". He was quoted saying, "If I were made dictator, I would have an accident centre in each large city, where cases could be properly treated, and for as long as necessary. I would have beds for adults in each orthopaedic hospital and small county hospital to act as casualty clearing stations."

Robert Jones' work in orthopaedics helped expand it from the focus of caring for crippling diseases in children to the treatment of adults with disorders of the musculoskeletal system and the management of acute injuries ${ }^{7}$. He published a wide variety of orthopaedic Artciles. In 1916, he published a textbook of orthopaedics entitled 'Injuries of Joints' which explained how to systematically deal with the diagnosis and treatment of acute fractures.

In 1918, Robert Jones instigated the foundation of the British Orthopaedic Association ${ }^{6}$.

\section{Radiography}

Robert Jones' progressive attitude was exemplified by his integration of X-rays in his practice. In 1895, Wilhelm Röntgen announced his discovery of X-rays. News quickly reached Robert Jones, via a translation of the Frankfurter Zeitungnewspaper by a volunteer at his Sunday clinic in Liverpool. The following year, in 1896, he went to Germany and returned with his own radiographic apparatus, using it to complement his own practice. With Thurston Holland, he took probably the first X-ray in Britain to locate a bullet in a boy's wrist. This case was published in The Lancet in February $1896^{8}$.

Though Robert Jones only thought of the radiograph as an adjunct initially, he began to increasingly value it in his practice, and an article he published in 1932 stated that, "Radiography here, as in all branches of medicine, is an essential aid to diagnosis. No matter how experienced we may be, we cannot afford to dispense with it, even in the apparently simple and obvious case." 9

\section{First World War:}

In 1914, when the First World War broke out, Robert Jones, 57 years old then, joined as Captain of the Army Reserve. He was quickly promoted to Major General. During his time at the frontlines, he noticed that the treatment for fractures both at war and domestic hospitals were insufficient. His efforts to promote better after-care and rehabilitation of the wounded soldier led to the establishment of specialized military orthopaedic hospitals, where he was assisted by many American surgeons ${ }^{3}$.
He also advocated the use of the Thomas' splint for the initial treatment of a femoral fracture, to immobilize the fracture without much loss of time and before much handling of the limb. The consequence of this change was that patients arrived at the Casualty Clearing Station in a better condition, with a lower incidence of shock. This decreased both morbidity and mortality rates from this injury ${ }^{2}$.

In 1917, he wrote 'Notes on Military Orthopaedics', which became indispensable throughout the United Kingdom to surgeons who were not proficient at fracture care at that point in time.

\section{The Jones Fracture:}

While on a dancing outing, Robert Jones accidentally trod on the outer side of his foot and felt a give midway down his foot. Immediately he suspected a rupture of his peroneus longus tendon. However, after careful examination, he realized that the tendon was still intact.

With the help of his colleague, David Morgan, an X-ray of his foot was done and a fracture of his fifth metatarsal was noticed, about three quarters of an inch from its base.

He wrote a paper, published in the Annals of Surgery in 1902, on six patients, the first being himself, on the fracture described. This debunked the popular belief then that all metatarsal fractures were caused by direct trauma. It was caused in reality, by a cross-strain placed on the fifth metatarsal, commonly when body weight was expended on the bone, with the heel off the ground and foot inverted. Robert Jones thus had sustained the fracture which he described eponymously the Jones fracture ${ }^{11}$.

Other Surgical Techniques, Procedures and Acknowledgments. The Robert Jones bandage

A bulky compression dressing was often used on limbs after trauma and elective orthopaedic operations aimed at providing firm and evenly distributed pressure is named for him. This bandage increased the compartment pressure, thereby helping to reduce bleeding, tissue oedema, effusions and haemarthroses. Though specific references to the bandage were rarely made in the writings of Robert Jones and his pupils, Watson-Jones and McMurray, two orthopaedic surgeons, indicated that Robert Jones routinely used it in his practice. This was described as a "pressure crêpe bandage over copious wool dressing". However due to lack of accurate documentation on the bandage, there has been variation in the techniques and components used in the bandage.

A commonly accepted construct of the bandage includes a sterile gauze pad layer placed over the wound, followed by a thick layer of cotton wool and a final outer elastic layer, with the entire limb bandaged ${ }^{12}$. 


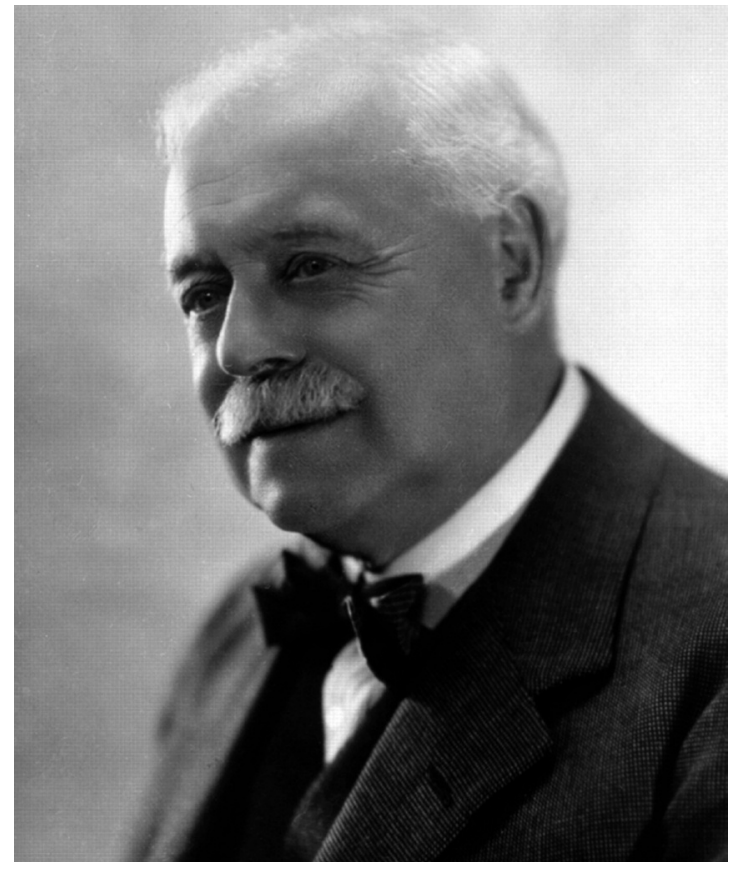

Fig. 1: Sir Robert Jones

From "The influence of Sir Robert Jones on the founding and development of orthopaedic surgery at the Mayo Clinic." By Morrey B. F.

\section{Version}

In tendon transplantation one must insist on:

1. The over-correction of deformity as a preliminary measure.

2. The removal of skin flaps to secure uninterrupted continuity of the over-correction. Ellipses of skin were removed from the paralysed side of a joint and the incision closed to hold the over-corrected position.

3. The direct and not angular deflection of the tendon.

4. The free tunneling in the one plane through soft tissues.

5. The firm suturing into periosteum or bony groove.

6. The careful choice, tension, and nursing of the transplanted tendon.

7. The maintenance of the hyper-corrected position until voluntary power is assured to the tendon.

8. The deflection of body weight during walking from the reinforcing tendon.

In addition to these, it may sometimes be well to shorten the paralysed tendons and prevent the overaction o their opponents by tenotomy.

Al my hospital transplantations are treated as outpatients, and return to their homes on the day of operation, and no difficulties of any kind arise therefrom.

Fig. 3: Robert Jones' Rules for Tendon Transfer

\section{Robert Jones' Rules for Tendon Transfer}

Robert Jones first enunciated the rules for tendon transfer operations in 1908, giving guidelines to such procedures.

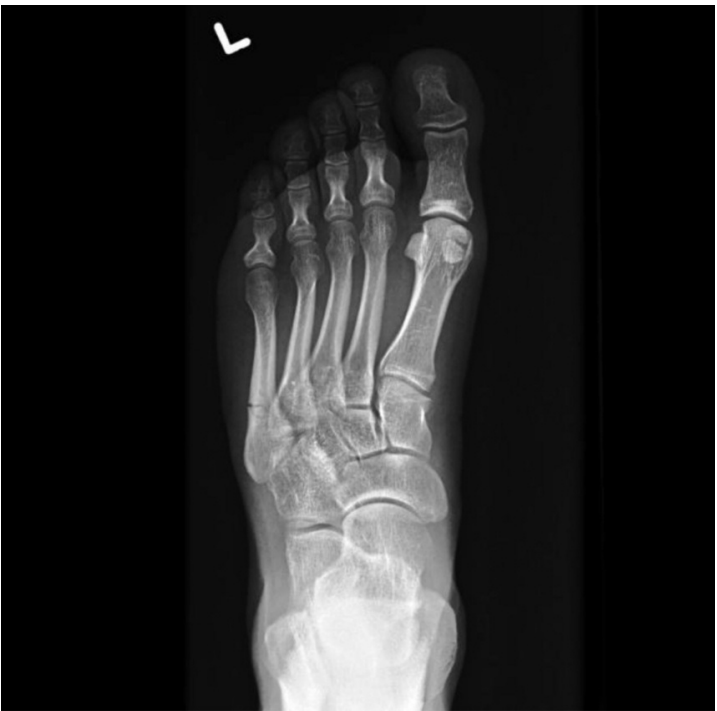

Fig. 2: Jones Fracture 5th metatarsal

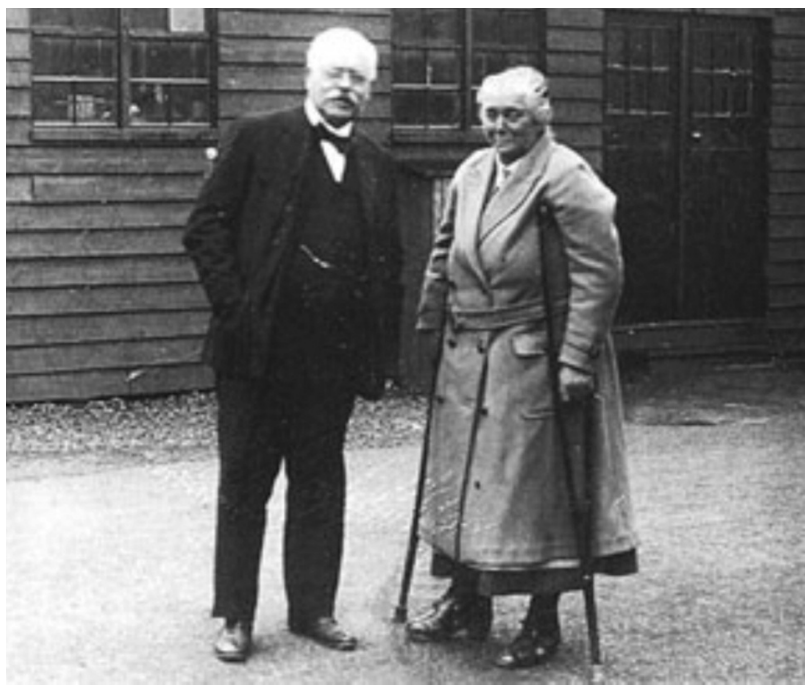

Fig. 4: Robert Jones and Agnes Hunt

From HHARP: the Historic Hospital Admission Records Project Kingston University.

McMurray later edited these for his textbook of orthopaedics in $1921^{13}$.

The operation described by Robert Jones, came to be called the Robert Jones operation of transfer of the extensor halluces longus tendon for claw deformity of the big toe

\section{Notes in Military Orthopaedics}

In his paper published in the British Medical Journal in 1916, Robert Jones provided guidelines on the treatment of orthopaedic problems in soldier's feet, and common foot deformities. These included claw feet, hallux rigidus, hallux valgus and metatarsalgia. This was an important publication for surgeons in Britain at that time, as the orthopaedic practice was not well established there yet ${ }^{14}$. 


\section{Work in General/Public Health}

Following his uncle's footsteps, Robert Jones opened a free Sunday morning clinic. He paid frequent visits to a small home at Basechurch in Shropshire, opened by Agnes Hunt, to see patients. This home was popular with the disabled and children before they underwent operations. This grew into what would be later known as the Robert Jones and Agnes Hunt Orthopaedic Hospital in Oswestry.

While on duty in the frontlines in World War I, Robert Jones observed that the War Office only paid attention to soldiers disabled due to the war up to the moment they were discharged from the military hospital. These people were unable to return to combat duties. Robert Jones took up the initiative to help facilitate the recovery of this group of soldiers and took it upon himself to aid in their rehabilitation and reintegration back into the community. He held many curative workshops at Shepherds Bush Hospital in London, benefitting many soldiers. As society then was prejudiced against the disabled, in the later part of his life and work, Robert Jones dedicated his time towards creating the social acceptance for this group of people.

Robert Jones showed the path for the total care of crippled children at Basechurch, and for disabled men at Shepard's Bush Hospital. After the First World War, Robert Jones took up the challenge of the prevention of crippling disease ${ }^{4}$. He started a national scheme for the detection, treatment and training of cripples ${ }^{13}$.

At the end of his career, Sir Robert Jones published a paper entitled "Cure of the Crippled Children" with Robert Girdlestone of the University of Oxford. This paper was a critical analysis of the poor care of crippled children throughout England and included a proposed scheme to deal with its shortcomings.

Robert Jones' pioneer work in the field of orthopaedics paved the way for the formation of non-governmental organisations such as the Central Council for the Care of
Cripples and the Invalid Children's Aid Association with access to, and influence on, the ministries of health and education ${ }^{6}$.

\section{Other Positions and Titles}

In addition to those achievements mentioned above, Robert Jones was knighted for the advancements that he made in the usage of X-rays in orthopaedics during his time at the Alder Hey Children's Hospital, Liverpool. He also accepted the position as Senior Consultant at Harlow Wood Orthopaedic Hospital for a few years before visiting various parts of the United Kingdom during the last ten years of his life. In those years, he spoke and wrote personal statements to popularize his beliefs. By the time of Robert Jones' death, seventeen centres and associated clinics had been established.

Other appointments Robert Jones held included being a lecturer in Orthopaedic Surgery at the University of Liverpool, the President of the Orthopaedic Section of the International Congress of Medicine in 1909, as well as the President of the Orthopaedic Section of the Seventh International Conference of Medicine held in London ${ }^{2}$.

\section{Death and Legacy}

Robert Jones died on 14 January 1933, at the age of 73. His remains were laid to rest in Liverpool Cathedral, where a plaque to commemorate his achievements was placed ${ }^{10}$.

In his life as an orthopaedic surgeon, Robert Jones' work was not limited to just to development of orthopaedics. He was also concerned with the general health of society and led a committed life in eradicating the prejudice that society had towards the disabled. A pioneer of the orthopedic specialty, he transformed its practice from the focus of caring for crippled children to that of musculoskeletal diseases in adults. Undoubtedly, Robert Jones had heavy influence on the practice of orthopaedics. He helped in developing founding the specialty, establishing its importance in the medical world. 


\section{REFERENCES}

1. Watson, Frederick. The Life of Sir Robert Jones. Am J Public Health Nations Health. 1935; 25(4): 508-9.

2. Malkin SA. The Conquest of Disability. Ann R Coll Surg Engl. 1957; 20(2): 99-111.

3. Cope R. Robert Jones: father of modern orthopaedic surgery. Bull Hosp Jt 1995; 54(2): 115-23.

4. $\quad$ Sir Robert Jones, Bt., K.B.E., C.B., F.R.C.S., Br Med J. 1933 21; 1(3759): 123-5.

5. Klenerman L. The Evolution of Orthopaedic Surgery, London: Royal Society of Medicine Press, 2002; 6.

6. Le Vay D. The History of Orthopaedics: An Account of the Study and Practice of Orthopaedics from the Earliest Times to the Modern Era, Carnforth, Lancs, UK; Park Ridge, N.J., USA: Parthenon Pub. Group, 1990; 137-46.

7. Hagy M. "Keeping Up with the Joneses" The Story of Sir Robert Jones and Sir Reginald Watson-Jones Iowa Orthop J. 2004; 24: $133-7$.

8. Jones R, Lodge O. The discovery of a bullet lost in the wrist by means of the Roentgen rays. The Lancet 1896.(147): $476-7$.

9. Jones R. Manipulation as a Therapeutic Measure. Proc R Soc Med. 1932; 25(9): 1405-12.

10. Batchelor J.S. Robert Jones, his life and ours to day. Ann R Coll Surg Engl 1969; 44(6): 342-55.

11. Jones R. I. Fracture of the Base of the Fifth Metatarsal Body by Indirect Violence. Ann Surg. 1902; 35(6): 697-700

12. JD Brodell, DL Axon, CM Evarts. The Robert Jones Bandage. J Bone Joint Surg Br 1986; 68(5): 776-9.

13. Rang, Mercer. The story of orthopaedics. Philadelphia : W.B. Saunders, 2000;336-40, 14. Jones R. III. The Soldier's Foot and the Treatment of Common Deformities of the Foot. Br Med J 1916; 1(2891): 749-53.

15. Jones R. An Address On Orthopaedics and Tendon Transplantation. Br Med J. 1908 28; 1(2465): 728-32.

16. Morrey B. F. The influence of Sir Robert Jones on the founding and development of orthopaedic surgery at the Mayo Clinic Bone Joint J 2005; 87(1): 106-7. 